

\section{Proposta metodológica para a compreensão do lugar a partir do estudo do mapa}

Propuesta metodológica para la comprensión del lugar a partir del estudio del mapa

Methodological Proposal for the Understanding of the
Place Based on the Study of the Map

Joseane Gomes de Araújo*

Ione Oliveira Jatobá Leal**

\begin{abstract}
Resumo
O presente artigo tem como objetivo refletir sobre a utilização de mapas municipais para a construção do raciocínio geográfico a partir do estudo do lugar. Com base nisso, nesta pesquisa foram utilizados os seguintes procedimentos para estimular diferentes habilidades críticas: levantamento e análise das abordagens cartográficas escolares, apresentação da proposta aos coordenadores pedagógicos, levantamento de informações e elaboração de representações. Conclui-se que os mapas municipais permitem a construção de novos conhecimentos e inovações para o ensino do local.
\end{abstract}

\author{
Palavras-chave \\ Cartografia escolar, representação municipal, formação docente.
}

\footnotetext{
* Universidade do Estado da Bahia.

** Universidade do Estado da Bahia.
} 
Proposta metodológica para a compreensão do lugar a partir do estudo do mapa Joseane Gomes de Araújo / Ione Oliveira Jatobá Leal /

\section{Resumen}

Este artículo tiene como objetivo reflexionar sobre el uso de mapas municipales para la construcción del pensamiento geográfico a partir del estudio del lugar. Para tal fin, en esta investigación se utilizaron los siguientes procedimientos con el fin de incentivar diferentes habilidades críticas en los estudiantes: abordaje y análisis de la cartografía escolar, presentación de la propuesta a los coordinadores pedagógicos, levantamiento de información y elaboración de representaciones cartográficas. Se concluye que los mapas municipales posibilitan la construcción de nuevos conocimientos e innovaciones para la enseñanza acerca del lugar.

\section{Abstract}

The purpose of this article is to reflect upon the use of municipal maps for the construction of geographical thought based on the study of the place. Accordingly, the researchers used the following procedures in order to encourage different critical skills: survey and analysis of school cartography approaches, presentation of the proposal to the pedagogical coordinators, gathering of information, and map making. It is concluded that municipal maps facilitate the construction of new knowledge and innovations for teaching about the place.

\section{Palabras clave}

Cartografía escolar, representación municipal, formación docente.

\section{Keywords}

School cartography, municipal representation, teacher training. 


\section{Introdução}

O trabalho com a cartografia escolar na educação básica é fundamental para a construção dos conceitos geográficos por meio de estratégias que estimule o pensamento, a argumentação e a leitura. Este trabalho está vinculado a pesquisa que objetiva a construção colaborativa de representações cartográficas municipal considerando as demandas dos professores de Geografia do Ensino Fundamental e as categorias e conceitos geográficos definidos pelos documentos oficiais que norteiam o ensino de Geografia.

Com a vivência no ensino de Geografia no ensino fundamental e na formação de professores na disciplina Cartografia Temática e Sistemática, Prática de Ensino e Estágio Supervisionado (UNEB), constatamos a quase inexistência de representações gráficas e cartográficas que favorecesse a construção de noções espaciais e conceitos geográficos a partir do lugar com vistas a potencialização de habilidades para leitura e compreensão de mapas. Apoiados na literatura sobre o ensino de Geografia e cartografia escolar, encontramos inúmeras lacunas para estudar os saberes de professores e os trabalhos com a cartografia escolar, e como esta, é ensinada na escola, especialmente na construção do conhecimento a partir do lugar.

Após vários debates e pesquisas sobre a temática, nas quais destacamos estudos já realizados por Almeida (2001, 2003, 2010 e 2011), Breda (2017), Castellar (2017), Callai (2013), Martinelli (1998, 2003), Simielli (1999), Souza e Katuta (2001), decidimos elaborar um projeto de extensão para investigar o material didático utilizado pelos professores das séries iniciais da rede municipal de Jacobina-Bahia e coletar dados juntamente com professores e coordenadores sobre as formas de representações que possibilitaria a direção na construção de noções cartográficas (localização, orientação, legenda, escala), bem como a base de conhecimentos que os professores necessitam para trabalhar a cartografia escolar.

A metodologia adotada se deu com a busca de documentos que regulamentam o ensino de Geografia e que são adotados pelas escolas municipais de Jacobina-Ba; a apresentação da proposta para os coordenadores pedagógicos e a escuta sobre a mesma para montagem de projeto de extensão, organização de equipe responsável pela coleta e elaboração de produtos cartográficos além da formatação e estruturação/adequação do material produzido.

\section{Abordagem teórica}

Uma das estratégias de se trabalhar a Geografia nas séries iniciais de forma a despertar o interesse dos educandos é trazer para a aula representações cartográficas de sua própria realidade. E o mapa do município pode ser uma boa opção para dinamizar a aula e inserir os conceitos geográficos e cartográficos a partir de referências do cotidiano dos estudantes. No dia a dia o cidadão pode fazer a leitura do espaço através de diferentes linguagens e a Cartografia, pode contribuir nessa tarefa com as representações gráficas e cartográficas. No entanto, ela não é trabalhada na educação básica dissociada dos conteúdos geográficos.

Francischett (1997) destaca que através do mapa é possível representar a abstração da realidade geográfica a partir de vária modalidades, tornando um veículo de comunicação entre o espaço real e sua representação. Sendo o mapa um meio de comunicação da informação o professor deverá ter domínio da linguagem cartográfica e de conceitos chaves para fazer uma leitura e interpretação eficaz dos mapas. Entretanto, se o professor não tiver o domínio dessas informações fica difícil haver uma contextualização dos conceitos da Geografia e os mapas se tornarão objetos de estantes das bibliotecas escolares.

De acordo com o exposto, Callai (2000) afirma que o conteúdo da geografia escolar tem sido na atualidade, o de descrever alguns lugares e problemas, não conseguindo dar conta de pensar o espaço a partir de suas contradições, visto que: Pensar o espaço supõe dar ao aluno condições de construir um instrumento tal, que seja capaz de buscar as informações/dados acerca do lugar e ao mesmo tempo poder organizar o conhecimento para refletir sobre o lugar onde reside. "Não apenas para entender determinado conteúdo, mas para usá-lo como possibilidade de construir a sua cidadania" (Callai, 2000, p. 69).

Segundo os Parâmetros Curriculares Nacionais (PCNS), no primeiro ciclo, o estudo de geografia deve abordar principalmente questões relativas à presença e ao papel da natureza e sua relação com a ação dos indivíduos, dos grupos sociais e, de forma geral, da sociedade na construção do espaço geográfico, o que nos faz crer que a paisagem local e o espaço vivido são as principais referências para que os professores realizem um bom trabalho inicial com as crianças. "Desde o primeiro ciclo é importante que os alunos conheçam alguns procedimentos que podem aprender a utilizar, mesmo que ainda o façam com pouca autonomia, necessitando da presença e orientação do professor" (Brasil, 1997, p. 128). 0 ensino e a prática contínua de procedimentos de pesquisa fazendo o uso dos mapas locais consequentemente aumentarão a chance de os alunos, ao final do ensino fundamental, alcançar os objetivos de geografia propostos pelos PCNS.

Consideramos que a leitura do mundo a partir de diferentes linguagens é fundamental para o exercício da vivência em sociedade. Uma forma de prática cidadã é a leitura e observação do espaço, no que concordamos com o exposto por Callai (2005):

Uma forma de fazer a leitura do mundo é por meio da leitura do espaço, o qual traz em si todas as marcas da vida dos homens (...) ler o mundo vai muito além da leitura cartográfica, cujas representações refletem as realidades territoriais (...) fazer a leitura do mundo não é fazer uma leitura apenas do mapa, ou 
pelo mapa, embora ele seja muito importante. É fazer a leitura do mapa da vida, construído cotidianamente e que expressa tanto as nossas utopias, como os limites que nos são postos, sejam eles do âmbito da natureza, sejam do âmbito da sociedade (culturais, políticos, econômicos). Ler o mundo da vida, ler o espaço e compreender que as paisagens que podemos ver são resultados da vida em sociedade, dos homens na busca da sua sobrevivência e da satisfação das suas necessidades. (p. 228).

Desse modo, toda informação fornecida pelo lugar ou grupo social no qual a criança vive é altamente instigadora de novas descobertas. Saber ler as informações do espaço vivido significa explorar a observação da paisagem e, assim, não se restringir à percepção das formas, mas perceber o significado de cada uma delas, levantando questões e verificando a sua espacialidade no espaço.

Nos últimos anos há um número crescente de pesquisas voltadas a elaboração de Atlas municipal com o intuito de ampliar o uso das representações cartográficas no ensino da Geografia. É visível para quem participa dos eventos que contemplam temáticas da Cartografia Escolar, o aumento de apresentação de trabalhos referente ao atlas municipal, priorizando o uso por parte de professores ou de alunos dos diversos níveis. Entretanto, nem sempre a elaboração desses mapas conta com a participação de professores do ensino básico ou com a participação de profissionais que atuam na escola. Almeida (2003), representa o grande marco nesta proposta do conhecimento cartográfico colaborativo, destacando a metodologia e os percursos para esta importante atividade que permite aos professores trabalharem conteúdos da Geografia/cartografia a partir do espaço local, numa escala municipal, como uma possibilidade de potencializar a aproximação do ensino com a realidade local. Também é preciso destacar os trabalhos de Janine Le Sann e Zacharias que coordena grupos de pesquisas responsáveis pela produção de vários atlas escolares de municípios mineiros e paulistas, já publicados, e outros em fase de elaboração.

Entende-se que as representações do mundo e espaços conhecidos são bastante antigas, apresentada em árvores, cavernas, papel entre outras formas. Atualmente, a tecnologia vem facilitando cada vez mais a elaboração de mapas de forma rápida e com certa precisão, principalmente com o acesso ao computador e softwares livres ou não, lembrando que nem todos têm acesso à tecnologia ou sabem lidar com a mesma. Além dos mapas municipais, os pré-mapas (fotografias aéreas, mapas mentais, e imagens de satélites) também são essenciais para informação sobre os lugares, além de despertar a curiosidade dos estudantes para novas descobertas.

O mapa é uma ferramenta didática que pode ajudar na construção de conceitos geográficos, porém, o acesso a mapas, atlas, globo terrestre e principalmente aos mapas municipais não é fácil, bem como a operacionalização das práticas docentes representa um desafio para os professores. Para Felbeque (2001):
Uma maneira de viabilizar a apresentação e uso dos mapas em sala de aula, foi a incorporação dos atlas escolares no ensino de Geografia. Os mapas municipais também são recursos para construção de conceitos geográficos pelos alunos facilitados por ser discutido e construir uma aprendizagem a partir da realidade local. (P. 39).

A preocupação com a elaboração de atlas municipal tem a ver com a dificuldade dos estudos sistematizados sobre os municípios e da disponibilização de dados cartográficos para servir de suporte para as pesquisas e para o ensino na educação básica. Sobre o estudo do lugar Callai (1999) afirma: que esse, se pode ser considerado um dos principais arranjos para construção didática da disciplina escolar. Nesse ponto de vista, seus sujeitos-professores e alunos-devem conhecer a relevância de ensinar e aprender Geografia, a partir dessa categoria de análise do espaço geográfico, para a compreensão do mundo.

Portanto, o estudo do município permite que o "aluno constate a organização do espaço, que possa perceber nele a influência e/ou interferência dos vários segmentos da sociedade, dos interesses políticos e econômicos ali existentes e também de decisões externas ao município, confrontando-as inclusive com interesses locais e da população que ali vive" (Callai, 1999 p. 75). Silva e Compiani (2005) afirmam que:

Atualmente, observa-se uma efervescência na produção de atlas escolares, principalmente aqueles destinados à escala municipal. Este material é de extrema importância para o estudo do espaço local e está de acordo com as novas orientações curriculares. Eles trazem informações atualizadas e organizadas por temas, auxiliando professores e alunos na construção do conhecimento. (P. 14618).

Os referidos autores afirmam ainda que o ensino do lugar por meio dos atlas escolares conduz à compreensão da cidadania como participação social e política. A apropriação do espaço de representação traz a compreensão da geografia escolar e de seu objeto de estudo.

Percebe-se a relevância da cartografia escolar, uma vez que existem várias literaturas constatando a importância dos mapas, proposta metodológicas para educação cartográfica, habilidades de leitura e confecção de mapas, a exemplo de: Oliveira (1978), que destaca a importância dos mapas como uma forma de comunicação; Passini (1998), por atribuir ao mapa uma importância mais abrangente quando afirma que "a possibilidade de ler mapas é importante para se educar o aluno e as pessoas em geral para a autonomia". Machado e Oliveira (1980), investigam o "papel dos mapas e pré-mapas na percepção geográfica do espaço dos adolescentes e verificam a transposição das relações espaciais percebidas em uma situação geográfica conhecida para outra situação não conhecida" (p. 49). Paganelli, Martinelli, Rosely, Almeida entre outros pesquisadores, 
também afirmam que as representações são importantes instrumentos para o conhecimento e representação da realidade, sendo assim indispensável ao trabalho geográfico.

Le Sann (1997) enfatiza que o "papel fundamental da Geografia é localizar, representar, evidenciar relações lógicas, possibilitar explicações com os mapas ou outros recursos cartográficos, e mesmo de posse dessas ferramentas, são mal utilizados nas escolas, portanto os educadores necessitam encontrar caminhos que facilitem e incentivem a sua plena utilização" (p. 25). Ainda em relação à Cartografia, Simielli (1999) faz uma consideração muito pertinente: "Devemos e podemos usar cada vez mais a cartografia em nossas aulas, pois ela facilita a leitura de informações para os alunos e permite um domínio do espaço de que só os alfabetizados cartograficamente podem usufruir" (p. 108). Dessa forma, a Cartografia é um dos elementos que não deve faltar em sala de aula.

Quanto aos mapas municipais, é necessário que haja uma linguagem acessível ao público para o qual é destinado sem, no entanto, perder o rigor científico, isto é, um material que proporcione a discussão de conceitos e compreensão do espaço de vivência. Todavia, como afirma Silva e Sampaio (2014), o texto acerca do lugar deve conter a presença bem dosada de textos literários, artigos e reportagens de jornais e revistas visando enriquecer o conteúdo, possibilitando ao aluno uma visão ampla e diversificada sobre determinado assunto, do mesmo modo as representações cartográficas irão conduzir o professores e estudantes na relação ensino/aprendizagem visando à construção de conhecimento por meio de mapas municipais e, portanto, conhecimento do lugar.

Nessa perspectiva de priorizar o ensino do lugar vivido pelo aluno, Castellar (2010) afirma que "compreender a geografia do lugar em que vive o aluno significa conhecer e apreender intelectualmente a cidade, a cultura urbana, a paisagem, os fluxos de pessoas e mercadorias, as áreas de lazer, os fenômenos e objetos existentes no espaço urbano e rural" (p. 44). Assim, pode-se afirmar que trazer para sala de aula o cotidiano vivido pelo aluno poderá proporcionar aos mesmos o conhecimento de sua realidade e a vivência cotidiana, e com o uso dos mapas do município, proporcionar a visão integral da representação espacial da cidade, dinamizando o processo ensino e aprendizagem e a reflexão sobre a realidade.

\section{Materiais e métodos}

Para desenvolver esse trabalho houve etapas importantes como o levantamento e análise das abordagens da cartografia escolar nos livros didáticos adotados pelas escolas do município; reunião com coordenadores pedagógicos para apresentar a proposta e promover um debate sobre a contribuição das representações cartográficas do município para o ensino de Geografia, levantamento e organização de informações geográficas úteis para o estudo do local, bem como a definição de programas digitais para a elaboração das representações.
O banco de dados foi construído a partir de acervo de material já produzido por órgãos oficiais (Instituto Brasileiro de Geografia e Estatística, Secretaria de Meio Ambiente do Estado da Bahia), pesquisadores da área de estudo e atividade de campo da equipe desta pesquisa. Buscamos com esta investigação nos aproximar de uma análise das práticas docentes dos professores do $1^{\circ}$ ao $5^{\circ}$ ano do Ensino Fundamental da rede municipal do município de Jacobina-Bahia.

\section{Resultados e discussão}

As buscas de abordagens da cartografia nos livros didáticos do $1^{\circ}$ ao $5^{\circ}$ ano, Coleção Porta Aberta (Ciências Humanas e da Natureza), adotados pela rede municipal de ensino nos revelou que são poucos conteúdos que remetem a uma representação cartográfica para explorar o raciocínio geográfico nas séries iniciais.

Quadro 1. Os conteúdos cartográficos nos livros didáticos de Geografia nas Escola Municipais de Jacobina/BA.

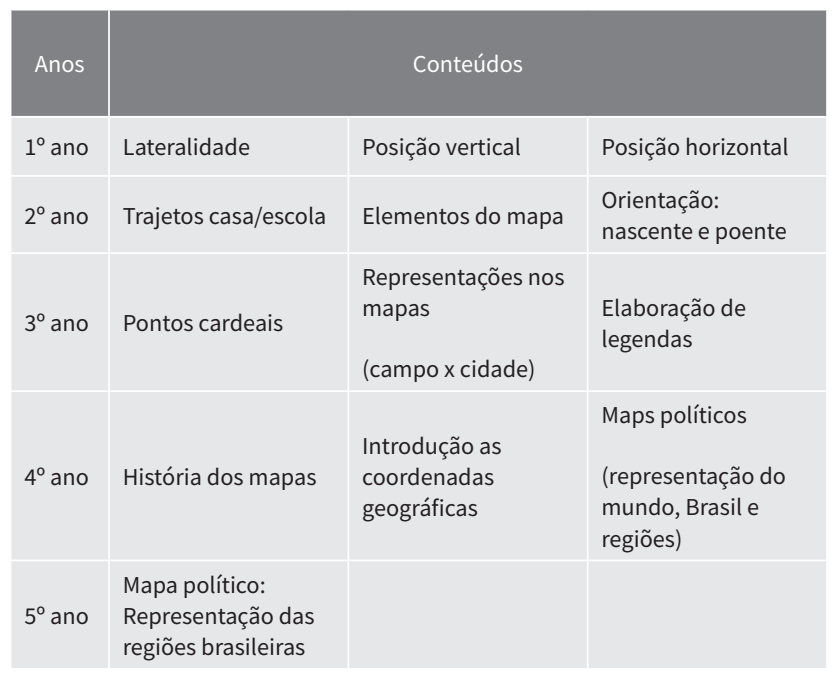

Fonte: Livros didáticos de Geografia do Ensino Fundamental I. Organizados pelos monitores do projeto (2018).

A abordagem desses conteúdos a partir das representações e dos escritos nos livros, são pontuais e restritas, exige um aprofundamento/esclarecimento dos professores a partir dos seus saberes e práticas. Essa intervenção é importante para que o aluno compreenda o mapa como um instrumento metodológico para representar o conhecimento e não apenas como uma ilustração do conteúdo.

Simielli (1999) propõe o trabalho com diferentes mapas para diferentes usuários do ensino fundamental, pois este é o momento em que o aluno tem que iniciar-se nos elementos da representação espacial. A partir das conversas com os coordenadores das escolas do ensino fundamental, 
elaboramos temáticas para serem estudadas/pesquisadas e representadas do local, sendo: localização e subdivisão do município; município e seus limites territoriais; sede do município com divisões por bairros; vias de acesso/estradas do município; hidrografia; vegetação; clima; pluviosidade; geologia; principais serviços públicos; principais atividades econômicas; atividades turísticas e mineração.

Coletamos dados em diferentes fontes e elaboramos um conjunto de mapas para representar esses elementos geográficos com destaque para os aspectos físico, econômico, ambiental e político do município de Jacobina. A pesquisa em órgãos municipais (secretaria de planejamento, agricultura, educação, saúde, meio ambiente e coordenação de turismo) para obtenção de informações mais precisas e atuais não foi bem-sucedida, pois estes órgãos ainda não apresentam banco de dados organizados com levantamentos da área de estudo. De acordo com Simielli (1999),

Devemos iniciar oferecendo elementos para que a criança de $1^{\text {a }}$ a $4^{\mathrm{a}}$ séries do ensino fundamental ou de níveis que necessitem de alfabetização cartográfica compreendam os processos necessários para a realização das representações gráficas, sobretudo os mapas. Em outras palavras, a ideia é educar o aluno para a visão cartográfica (p. 97).

Elaboramos textos explicativos sobre cada representação evidenciando os conceitos geográficos destacado em cada representação para apoiar nas análises por meio das situações do cotidiano do estudante.

Figura 1. Mosaico de mapas do munícipio de Jacobina/BA

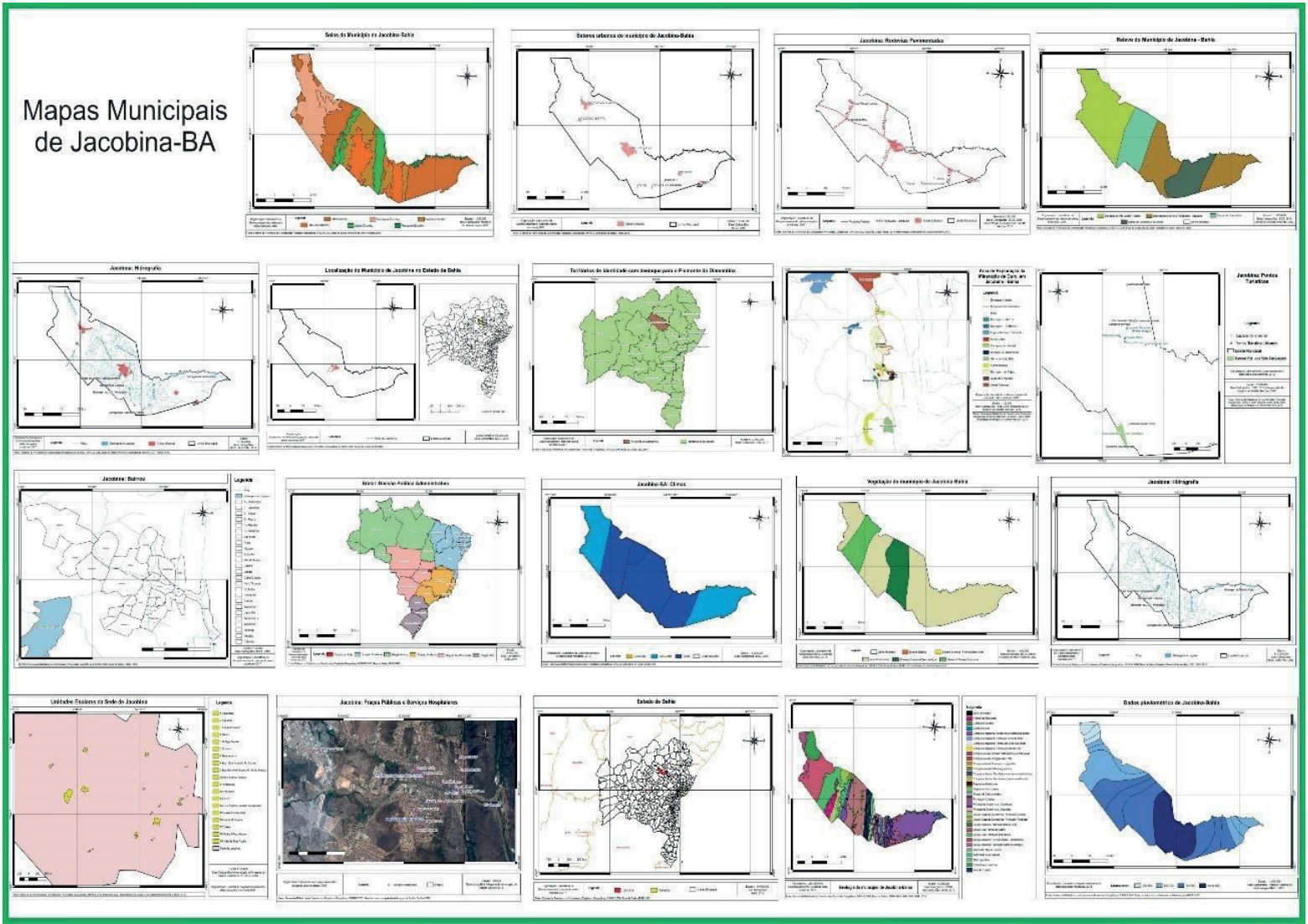

Fonte: Laboratório de Cartografia e Geoprocessamento-UNEB. Elaborado pelos monitores do projeto (2018). 
A proposta tornou-se motivadora por tratar de problemáticas locais vivenciadas por coordenadores, professores e estudantes. Apesar de ainda não ser aplicada em sala de aula, a fascinação com a contemplação do material produzido já revela que a elaboração de mapas municipais pode gerar um contexto significativo de ensino e aprendizagem capaz de envolver professores e alunos na busca por conhecimentos geográficos que dizem respeito às suas vivências.

O grande desafio da Geografia escolar para a compreensão do mundo, é, portanto, como fazer a leitura do lugar, como compreender o contexto em que se insere a escola, como entender o dia a dia da vida das pessoas que ali vivem. E isso permite compreender como o conhecimento cotidiano pode se constituir em referência para o conhecimento escolar. (Callai, 2013, p. 34).

As iniciativas de trabalhos com representações cartográficas municipais no ensino das séries iniciais é algo novo e recente na incorporação das práticas dos professores da pesquisa, pois eles estão acostumados aos mapas dos livros didáticos e em alguns casos dos atlas escolares que constam planisférios e mapas temáticos mundiais e regionais. Sob a ótica de análise desta investigação, pode-se afirmar que os mapas municipais para ser utilizado em sala de aula representa a possibilidade de construção de novos conhecimentos e inovações para o ensino da localidade, permitindo tanto para os alunos como aos professores tornarem-se conhecedores das características do município e da organização do espaço de vivência.

\section{Considerações finais}

Essa experiência revela a necessidade de produzir mapas do município para a alfabetização cartográfica e a construção do raciocínio geográfico a partir das aulas de Geografia. A discussão proposta nesta pesquisa está relacionada com a dimensão do conhecimento da cartografia escolar e a operacionalização das práticas docentes, a partir de uma reflexão que apresente a contribuição da cartografia escolar para a compreensão da Geografia do local.

O processo de ensino e aprendizagem são desafios permanentes para os professores da escola fundamental e o trabalho com a cartografia escolar (uso dos mapas em sala de aula) a partir do cotidiano dos sujeitos, propicia o domínio da linguagem cartográfica, fundamental para desenvolver o raciocínio geográfico.

Espera-se que conhecendo os materiais que os professores utilizam em sala de aula e os seus anseios a respeito dos materiais cartográficos que poderão auxiliar no seu trabalho, seja possível o fortalecimento de um diálogo e colabore na construção de propostas para o ensino da geografia pela cartografia.

\section{Referências}

Almeida, R. (2001). Do desenho ao mapa. São Paulo: Contexto.

Almeida, R. (2003). Atlas municipais elaborados por professores: a experiência conjunta de Limeira, Rio Claro e Ipeúna. Cad. Cedes, 23(60), 49-168.

Almeida, R. (2010). Cartografia Escolar. São Paulo: Contexto.

Almeida, R. (2011). Novo rumos da cartografia escolar: currículo, linguagem e tecnologia. São Paulo: Contexto.

Brasil, Secretaria de Educação Fundamental. (1997). Parâmetros Curriculares Nacionais: história, Geografia. Brasília: MEC/SEF.

Breda, T. (2017). Jogos geográficos na escola: possibilidades para trabaIhar noções espaciais e cartográficas. In D. Richter e L. Campos (Eds.), Cartografia Escolar (pp. 29-49). Goiânia: Editora espaço acadêmico.

Callai, H. (1999). O estudo do município ou a geografia nas séries inicias. In A. Castrogiovanni, H. Callai, N. Schaffer e N. Kaercher (Eds.), Geografia em Sala de Aula: práticas e reflexões. Porto Alegre: Editora da UFRGS.

Callai, H. (2000). Estudar o lugar para compreender o mundo. In A. Castrogiovanni (Ed), Ensino de Geografia: Práticas e Textualizações no cotidiano (pp. 69-134). Porto Alegre: Mediação.

Callai, H. (2005). Aprendendo a ler o mundo: a geografia nos anos iniciais do ensino fundamental. Cad. Cedes, 25(66), 227-247.

Callai, H. (2013). A formação do profissional da Geografia: o professor. ljuí: Ed. Unijuí.

Castellar, S. (2010). Educação: Formação e didática. In E. Morais e L. Moraes (Eds.), Formação de professores: conteúdos e metodologias no ensino de Geografia (pp. 39-57). Goiânia: Nepeg.

Castellar, S. (2017). Cartografia escolar e o pensamento espacial fortalecendo o conhecimento geográfico. Revista Brasileira de Educação em Geografia, 7(13), 207-232.

Felbeque, R. (2001). Atlas escolares: Uma análise das propostas teórico-metodológicas. Boletim de Geografia, 19(2), 36-41.

Fracischett, M. (1997). A Cartografia no ensino da Geografia. Construindo os caminhos do cotidiano. Francisco Beltrão: Grafit.

Le Sann, J. (1997). Mapa: um instrumento para apreender o mundo. Revista Geografia e Ensino, 6(1), 25-30. 
Proposta metodológica para a compreensão do lugar a partir do estudo do mapa Joseane Gomes de Araújo / lone Oliveira Jatobá Leal /

Martinelli, M. (1998). Gráficos e mapas: construa-os você mesmo. São Paulo: Moderna.

Martinelli, M. (2003). Os mapas da geografia e cartografia temática. São Paulo: Contexto.

Silva, L. e Sampaio, A. (2014). Livros didáticos de geografia: uma análise sobre o que é produzido para os anos iniciais do ensino fundamental. Revista Caminhos de Geografia, 15(52), 173-185.

Silva, L. e Compiani, M. (2005). O estudo do lugar e a fundamentação geográfica dos atlas escolares municipais no Brasil. X Encontro de Geógrafos da América Latina.
Simielli, M. (1999). Cartografia no ensina fundamental e médio. In A. Carlos (Ed.), A Geografia na Sala de Aula (pp. 92-108). São Paulo: Contexto.

Souza, J. e Katuta, A. (2001). Geografia e conhecimentos cartográficos: a cartografia no movimento de renovação da geografia brasileira e a importância do uso de mapas. São Paulo: Unesp. 